\title{
Does Metacognitive Strategy Instruction Indeed Improve Chinese EFL Learners' Reading Comprehension Performance and Metacognitive Awareness?
}

\author{
Lixia Pei \\ School of Foreign Languages, Suzhou University of Science and Technology, Suzhou, China
}

\begin{abstract}
This article reports an experimental study of reading comprehension among lower-intermediate learners of English as a foreign language in China. A sample of 66 participants underwent a program of metacognitive strategy instruction in reading lasting 8 weeks. Measures were taken of their reading comprehension performance and their metacognitive awareness before and after the instruction. Results show that EG and CG do not reveal any significant differences before and after instruction both in reading comprehension test and their reported metacognitive strategies uses and reasons are given in the discussion part.
\end{abstract}

Index Terms - metacognitive strategy instruction, Chinese EFL learners, reading comprehension performance, metacognitive awareness

\section{INTRODUCTION}

When it comes to the developments in L2 and EFL reading research, Grabe (1991) mentions reading is probably the most important skill for language learners and points out that the crucial importance of the reading skill in academic contexts had led to considerable research on L2 and EFL reading. According to Sheorey and Mokhtari (2001), many students entering higher education are not prepared for reading demands, which is often due to their low level of reading strategy knowledge and lack of metacognitive control. Reading strategies knowledge uses reveal about the way readers manage their interactions with written text. Recent research has focused on metacognitive awareness, or metacognition, i.e. cognition of cognition. These studies investigate the relationships among metacognitive awareness, strategy use and reading comprehension (e.g.Sheorey \& Mokhtari, 2001; Dhieb-Henia, 2003; Malcolm, 2009).

\section{LITERATURE REVIEW}

\section{A. Metacognition and Metacognitive Strategy in Reading}

According to Flavell (1979), reading in L1 or L2 is a "cognitive enterprise" which occurs as a result of the interaction among the reader, the text, and the context in which reading takes place. Malcolm (2009) concluded that the important elements of skillful reading include not only the ability to decode text rapidly, accurately and fluently (at the orthographic, lexical, structural and textual levels) but also background and world knowledge or schemata, reading experience, interest, cognition, motivation and reading purpose. Other researchers have emphasized the importance of vocabulary knowledge, familiarity with text type and genre as crucial elements of effective reading (Block, 1992; Grabe, 1991; Dhieb-Henia, 2003).

Reading strategy investigation in L1, L2 and EFL settings suggested that most of the comprehension activities of efficient readers take place at the metacognitive level, as shown by studies on the reading strategies used by successful and less-successful readers (Carrell et al., 1989; Sheorey \& Mokhtari, 2001; Wen, 2003). Carrell et al. (1989) suggested that successful use of reading strategies was largely dependent on the awareness of the use of these strategies according to the purpose of the task or the problem to be solved. Therefore, researchers have begun to recognize the significant role of metacognitive awareness or metacognition in reading comprehension.

According to Flavell (1979), metacognition consists of both metacognitive knowledge and metacognitive regulation. Metacognitive knowledge is one's knowledge of the cognitive process in relation to three variables that affect the outcomes of the "cognitive enterprise", namely, reader variable (beliefs about oneself or others as a cognitive processor), task variable (understanding of the nature and demand of tasks), and strategy variable (perceptions about strategies and strategy use that facilitate learning). While metacognitive knowledge is consciousness-focused, metacognitive regulation is executive in nature, working on the basis of the metacognitive knowledge and referring to people's management of their cognitive processes to ensure realization of learning goals (Zhang \& Wu, 2009).

Applied to reading, metacognitive awareness includes readers' conscious awareness of strategic reading processes, of 
the reading strategy repertoires, and of their actual utilization of the strategies to maximize text comprehension (Sheorey \& Mokhtari, 2001). Carrell et al. (1989) and Auerbach and Paxton (1997) considered metacognitive awareness----planning and consciously executing appropriate actions to achieve a particular goal----to be a critical element of proficient and strategic reading. According to Auerbach and Paxton (1997), such metacognition "entails knowledge of strategies for processing texts, the ability to monitor comprehension, and the ability to adjust strategies as needed" ( $p$ 240-41). The consensus view is that strategic awareness and monitoring of the comprehension process are critically important aspects of skilled reading.

Sheorey and Mokhtari (2001) identified ten metacognitive strategies in reading, which are setting purpose for reading, previewing text before reading, checking how text content fits purpose, noting text characteristics, determining what to read, using text features, using context clues, using typographical aids, predicting or guessing text meaning and confirming predictions.

\section{B. Metacognitive Strategy Instruction in Reading}

According to Carrell et al. (1989), reading instruction involved either direct instruction of decoding skills or informal teaching of comprehension. Our concern in this research is with the former, that is, relatively direct or explicit instruction in comprehension. Explicit strategy instruction raises learners' consciousness both of their own strategy use and of the existence of other strategies (Oxford, 1990). In terms of the mode of comprehension instruction, Reuztel et al. (2005) pointed out that much importance has been attached to the instruction of cognitive strategy, which has evolved from the teaching of single cognitive comprehension strategy in isolation to the teaching of multiple "set" or ""family" of cognitive comprehension strategies in coordinated use. While metacognitive control, in which the reader consciously directs the reading process, is a particularly important aspect of strategy reading. Therefore, metacognitive strategy instruction appears to be much more critical in nature compared to the instruction of cognitive comprehension strategy.

The Cognitive Academic Language Learning Approach or CALLA (O'Malley and Chamot, 1990) is utilized as the model of strategy instruction in this study. It focuses on explicit instruction in learning strategies. The model is presented through five basic phases: preparation, presentation, practice, evaluation, and expansion. In the Preparation phase, teachers provide advance organizers about the lesson, and students identify what they already know about a topic, using elaboration as a strategy. In the Presentation phase, teachers provide new information to students, using techniques which make their input comprehensible. Teachers can use advance organizers and encourage the use of selective attention, self-monitoring, inferencing, summarizing, and transfer. In the Practice phase, students engage in activities in which they apply learning strategies, often in cooperative small-group sessions. In the Evaluation phase, students reflect on their individual learning and plan to remedy any deficiencies they may have identified. Finally, in the Follow-Up Expansion phase, students are provided with opportunities to relate and apply the new information to their own lives, call on the expertise of their parents and other family members, and compare what they have learned in school with their own cultural experiences (as cited in Takallou, 2011 ).

Several studies investigated the effect of using different metacognitive strategies in reading in classroom context. For example, Carrell et al. (1989) investigated two types of metacognitive strategy training for ESL reading, which are semantic mapping and the experience-text-relationship (ETR) method, and concluded that metacognitive strategy instruction is effective in enhancing second language reading, and that the effectiveness of one type of training versus another may depend upon the way reading is measured. Dhieb-Henia (2003) reported how metacognitive strategy training influenced upper-intermediate readers' declarative and procedural knowledge, and their choice and use of strategies while reading research articles in the context of English for specific purpose. The findings showed that such training improved subjects' familiarity with and proficiency in reading research articles. Takallou (2011) reported the effect of metacognitive strategies instruction on learners' reading comprehension performance regarding authentic and inauthentic texts in EFL context and the strategies consisted of planning and self-monitoring. The results showed that subjects under the instruction performed much better in the authentic reading comprehension test. To summarize, literature on metacognitive strategy instruction in L2 reading mainly consists of task-based and context-oriented, in which subjects' proficiency level needs to be taken into account. Despite the importance and necessity of strategy instruction claimed by many scholars, limited empirical research of a set of metacognitive reading strategies instruction in this area was carried out. One area still unclear about reading strategy instruction is to what extent EFL learners' reading comprehension performance and metacognitive awareness are improved by means of an intensive period of metacognitive strategy instruction.

In China, English is taught as a foreign language. At present, English reading instruction in higher education is undergoing reforms. Teachers of English as a foreign language are encouraged to implement strategy instruction in order to help students cultivate reading strategies and form good reading habits. However, due to various reasons, instruction of reading strategies on tertiary level students, particularly in private university, is still characterized by the traditional comprehension-testing model. The traditional approach used texts primarily for vocabulary and grammar practice. The reading session usually starts with a pre-reading activity, followed by reading the text and finishing the vocabulary exercise and answering the multiple-choice and open-ended questions. It is assumed that students will naturally acquire the target strategies through implicit learning. However, students often complain that they do not see improvement in their reading ability or gain satisfaction from reading. Moreover, relatively little of the metacognitive strategy instruction research has been conducted in EFL reading setting. Considering metacognitive awareness in 
reading has been recognized to be critical to successful L2 and EFL reading, the purpose of this study is to find if, and to what extent, metacognitive reading strategy instruction can help EFL learners in private university read more efficiently and rapidly in the school-based material. The general hypothesis of this study is that metacognitive strategy instruction has a different effect compared to the traditional approach on students' performance on reading tests and their metacognitive awareness. The findings of this study are expected to generate some practical implications for EFL reading strategy instruction on tertiary level of lower-intermediate students in China or in other similar contexts where EFL reading strategy instruction is conducted with students from China.

This article reports a metacognitive strategy instruction study of reading in English as a foreign language. It is designed to answer the following two research questions:

1. Does the instruction of metacognitive strategy in reading have any significant effect on EFL learners' reading comprehension performance on school-based material?

2. Does the instruction of metacognitive strategy in reading have any significant effect on EFL learners' metacognitive awareness?

\section{Methodology}

\section{A. Participants}

The participants of the study were sixty-six freshmen of non-English major at Tianping College (a private college), Suzhou University of Science and Technology. There were thirty-one male and thirty-five female students. They were assigned into two classes and considered at lower-intermediate level of English proficiency according to their scores of English in the national matriculation test. None of the students have participated in the reading strategy training. Consent was sought and obtained from the participants.

\section{B. Design}

The study was a quasi-experimental research involving a pre- and post-test design with a sample of two intact classes. One class was randomly assigned as the experimental group (henceforth EG) and the other as the control group (henceforth CG). The two groups were checked in terms of their reading comprehension and metacognitive awareness using reading comprehension test and the revised Survey of Reading Strategy (SORS) (Sheorey and Mokhtari, 2001). The two groups enrolled in the English course which lasted for 16 weeks (one hour and thirty minutes a day, two days a week). The textbook used for this course was Zooming in: An integrated English Course and the researcher taught both two classes. Students in the CG were told that the researcher was interested in their approaches to reading over a period of time and how well they could understand a text in English, while all aspects of the strategy instruction were made transparent to the students in the EG. Considering the variable that the researcher expressed an interest in both groups in the natural classroom-based context, the Hawthorne effect would be neutralized or balanced out over a whole semester. The independent variables of the research were metacognitive strategy instruction in reading and the students' ability to read in English. The dependent variables of the research were the students' metacognitive awareness and their reading comprehension performance. To measure the students' ability to read in English and their reading comprehension performance, self-designed reading comprehension tests were used.

\section{Instrumentation}

There were two instruments for pre- and post-test measurements: Reading comprehension test and Survey of metacognitive strategies.

Reading comprehension test consists of two reading passages with multiple choices questions (hence force MCQs in pre-test and MCQsr in post-test), a translation of the English text into Chinese (hence force TRANS and TRANSr in post-test). Four reading passages (two at each test, involving ten multiple-choice items) were selected from National and Standardized College English Test Band 4 (2006 and 2008 version). Two texts (one at each test) selected from the $21^{\text {st }}$ century involved narrow reading requiring the participants to translate the English text into Chinese. Translation is acknowledged to be a reliable method for evaluating accurate understanding.

The translation text in pre-test consisted of 82 words and presented vocabulary and grammar levels consistent with the learners' current proficiency level, confirmed by the high-school curriculum and the teachers. In post-test, the translation text consisted of 104 words and was a little above the learners' current proficiency level and was confirmed by the teacher and the textbook being used.

In order to assess the reliability of the reading comprehension tests, they were piloted with a sample group of 40 students having characteristics similar to the target group. The researcher invited pilot students' comments on whether they had understood the texts and instructions. Its internal consistency reliability coefficient in pre-test was 0.62 and 0.71 in post-test. The interrater reliability coefficients for translation in pre-test and post-test were 0.57 and 0.63 respectively.

In this study, Sheorey and Mokhtari's (2001) Survey of Reading Strategies (SORS) was revised to measure the metacognitive awareness and perceived use of metacognitive reading strategies. Taking into account the participants' EFL proficiency level, the researcher translated the questionnaire into Chinese, which was to guarantee successful data collection and avoid comprehension difficulties that participants might encounter when given the English version. A 
professor in Suzhou University, who had a $\mathrm{PhD}$ in applied linguistics and was highly proficient in both English and Chinese, was invited to review the translated version for readability and accuracy. After the Chinese version was pilot tested, the overall reliability coefficient was 0.65 , which ensured the reliability of this study. The SORS consisted of 28 items, each of which used a five-point Likert scale ranging from 1 ("I never or almost never do this") to 5 ("I always or almost always do this"). The questionnaire was given before and after strategy instruction.

\section{Metacognitive Strategy Instruction}

O’Malley \& Chamot (1990) points out that metacognitive strategies are responsible for controlling other strategies and regards that they have their best effects if students are aware of other strategies that are available to them at the beginning of the course. The experimental group received explicit instruction on metacognitive strategies from the second day of the course. The students in the experimental group received 15 minutes of reading strategy instruction a week for 8 weeks. In each class hour they were taught one metacognitive strategy and they applied it to the required reading. Modifications were made to Sheorey and Mokhtari's (2001) metacognitive reading strategies in Survey of Reading Strategies (SORS) and the new version with eight strategies was given.

1. Setting purpose for reading

Having general purposes such as grasping the main idea and specific purposes when reading a text

2. Previewing texts before reading

Previewing the length and organization of the text

3. Inferring meaning

Using available information within the reading texts to guess the meaning of unfamiliar language items, and to predict outcomes

4. Using background information

Using knowledge gained from personal experience in the real world or in academic situations such as from classroom

5. Using text features and typographical aids

Making use of text features such as tables and typographical aids such as italics

6. Distinguishing known information from new information

Distinguishing between information that I already know and new information

7. Deciding on the text difficulty

Noting how hard or easy a text is to read

8. Predicting or guessing text meaning

Making use of the strategies mentioned above to predict or guess text meaning

The model of strategy instruction utilized in this study is the Cognitive Academic Language Learning Approach, or CALLA (ibid.), which focuses on explicit instruction in learning strategies.

\section{E. Data Collection and Analysis}

The data were collected from reading comprehension test and questionnaire. The researcher analyzed the data using descriptive statistical procedures as well as independent samples $t$-tests to examine whether significant differences existed between the two groups with respect to their reading comprehension performance and reported metacognitive awareness of reading strategy. A significance level of .05 was set for pre-test and at a more rigorous .01 for post-test because of the quasi-experimental and longitudinal nature of the study. Statistical Package for the Social Science (SPSS) version 12.0 for personal computers was used.

Regarding the scoring of reading comprehension test (two reading passages, a translation of text into Chinese), ten points were awarded for two reading passages with ten multiple-choice questions (one point for each question) both in pre-test and post-test. Twelve points were awarded for translation in pre-test and eighteen points for translation in post-test, three points for each sentence. Points were given half-correct (1.5 for 3-point sentences) and one-thirdly corrected translated sentences (1 for 3-point). Translation that was less than one-third correct was awarded zero point on the basis that incomplete information signified no comprehension. The reading comprehension test has a total score of 22 in pre-test and 28 in post-test. To ensure scoring objectivity, each translation work was evaluated by the researcher and her colleague.

The adapted SORS was administered at the beginning and the end of strategy instruction program. The students were informed of the purpose of the survey and of the fact that there was no right or wrong answers, and asked to express their honest opinion.

\section{RESULTS}

\section{A. Research Question 1}

The first research question was concerned with whether metacognitive strategy instruction in reading would result in better reading comprehension performance. Descriptive statistics are provided in table 1 for pretest and posttest. 
TABLE 1

DESCRIPTIVE STATISTICS FOR EG AND CG IN PRETEST AND POSTTEST

\begin{tabular}{llllll}
\hline & Group & $\mathrm{N}$ & Mean & $\begin{array}{l}\text { Std. } \\
\text { Deviation }\end{array}$ & $\begin{array}{l}\text { Std. Error } \\
\text { Mean }\end{array}$ \\
\hline Pretest & & & & 3.757 & .626 \\
& EG & 36 & 8.222 & 3.350 & .611 \\
Posttest & CG & 30 & 8.366 & 3.665 & .610 \\
& EG & 36 & 16.250 & 4.857 & .886 \\
\hline
\end{tabular}

Independent samples Test for EG and CG was carried out in pretest and posttest with instruction as the independent variable. No significant differences were found in both tests: Pretest, $\mathrm{F}=.663, p=.419$; and Posttest, $\mathrm{F}=2.040, p=.158$. Therefore, the two groups did not differ after the metacognitive strategy instruction in reading.

TABLE 2

INDEPENDENT SAMPLES TEST FOR EG AND CG IN PRETEST AND POSTTEST

\begin{tabular}{|c|c|c|c|c|c|c|c|}
\hline & \multicolumn{2}{|c|}{ Levene's Test } & \multicolumn{5}{|l|}{ t-test } \\
\hline & $\mathrm{F}$ & Sig. & $\mathrm{t}$ & $\mathrm{df}$ & $\begin{array}{l}\text { Sig. } \\
\text { (2-tailed) }\end{array}$ & $\begin{array}{l}\text { Mean } \\
\text { Diff. }\end{array}$ & $\begin{array}{l}\text { Std. Error } \\
\text { Diff. }\end{array}$ \\
\hline Pretest & .663 & .419 & -.163 & 64 & .871 & -.144 & .884 \\
\hline Posttest & 2.040 & .158 & -.778 & 64 & .440 & -.816 & 1.050 \\
\hline
\end{tabular}

\section{B. $\quad$ Research Question 2}

The second research question was concerned with whether metacognitive strategy instruction in reading would enhance EFL learners' metacognitive awareness. Independent samples test was carried out. Curiously enough, no significant differences were found between two groups in their reported metacognitive strategies.

TABLE 3

\begin{tabular}{|c|c|c|c|c|c|c|c|}
\hline & \multicolumn{2}{|c|}{ Levene's Test } & \multicolumn{5}{|l|}{ t-test } \\
\hline & $\mathrm{F}$ & Sig. & $\mathrm{t}$ & df & $\begin{array}{l}\text { Sig. } \\
\text { (2-tailed) }\end{array}$ & $\begin{array}{l}\text { Mean } \\
\text { Diff. }\end{array}$ & $\begin{array}{l}\text { Std. Error } \\
\text { Diff. }\end{array}$ \\
\hline MS1 & 1.056 & .308 & -2.365 & 64 & .021 & -.488 & .206 \\
\hline MS2 & .743 & .392 & .483 & 64 & .631 & .100 & .206 \\
\hline MS3 & 2.443 & .123 & -.246 & 64 & .807 & -.066 & .271 \\
\hline MS4 & 1.778 & .187 & 1.498 & 64 & .139 & .388 & .259 \\
\hline MS5 & .254 & 616 & .970 & 64 & .336 & .255 & .263 \\
\hline MS6 & 2.250 & .138 & -.229 & 64 & .820 & -.055 & .243 \\
\hline MS7 & .012 & .914 & -.325 & 64 & .746 & -.083 & .256 \\
\hline MS8 & .207 & .651 & -1.144 & 64 & .257 & -.272 & .237 \\
\hline MS1r & 3.165 & .080 & -.702 & 64 & .485 & -.172 & .245 \\
\hline MS2r & 8.323 & .052 & .220 & 64 & .826 & .044 & .201 \\
\hline MS3r & 1.403 & .241 & -.155 & 64 & .877 & -.033 & .215 \\
\hline MS4r & .028 & .868 & .467 & 64 & .642 & .111 & .238 \\
\hline MS5r & .586 & .447 & 1.141 & 64 & .258 & .305 & .267 \\
\hline MS6r & 10.645 & .059 & -.862 & 64 & .392 & -.161 & .186 \\
\hline MS7r & 1.223 & .273 & -2.279 & 64 & .026 & -.472 & .207 \\
\hline MS8r & .582 & .448 & -.459 & 64 & .648 & -.077 & .169 \\
\hline
\end{tabular}

\section{DISCUSSION AND CONCLUSION}

Though as Anderson (2002) states that the use of metacognitive strategies ignites one's thinking and can lead to higher learning and better performance and strategy research suggests that less competent learners are able to improve their skills through strategy instruction, the results of the experimental study do not coincide with the established research findings. EG and CG do not display any significant differences before and after instruction both in reading comprehension test and their reported metacognitive strategies uses.

The instruction program was conceptualized as low input in that only about 15 minutes were allocated to the reading strategy instruction for 8 weeks. Whether low input leads to no significant gains for EG awaits further research. To the end, face-to-face interviews were conducted with 6 participants in EG. The participants in this study are college students in private university in China. One point they expressed in common is that what has been taught in the instruction program is taken for granted for they have been instructed to do so since they were elementary school students. Therefore, they do not appreciate the reasons why such strategies are useful and do not show interest or enthusiasm in the instruction.

It is commonly accepted that metacognitive strategy instruction appears to be much more critical in nature compared to the instruction of cognitive comprehension strategy. Therefore, it is necessary to compare the effectiveness in terms of cognitive strategy instruction and metacognitive strategy instruction in reading with the same participants, which will be the next research topic. 


\section{REFERENCES}

[1] Anderson, N. J. (2002). The role of metacognition in second language teaching and learning. Retrieved from http://www.cal.org/resources/digest/0110anderson.html (accessed 20/3/2011).

[2] Auerbach, E. \& Paxton, D. (1997). "It's not the English thing": bringing reading research into the ESL classroom. TESOL Quarterly 31, 237-261.

[3] Block, E. (1992). See how they read: comprehension monitoring of L1 and L2 readers. TESOL Quarterly 26, 319-343.

[4] Carrell, P. L., Pharis, B. G., \& Liberto, J. C. (1989). Metacognitive strategy training for ESL reading. TESOL Quarterly 23, 647-677.

[5] Dhieb-Henia, N. (2003). Evaluating the effectiveness of metacognitive strategy training for reading research articles in an ESP Context. English for Specific Purposes 22, 387-417.

[6] Flavell, J. (1979). Metacognition and cognitive monitoring: a new era of cognitive-development inquiry. American Psychologist 34, 906-911.

[7] Grabe, W. (1991). Current developments in second language reading research. TESOL Quarterly 29, 269-297.

[8] Malcolm, D. (2009). Reading strategy awareness of Arabic-speaking medical students studying in English. System 37, 640-651.

[9] O’Malley, J. M. \& Chamot, A. U. (1990). Learning strategies in second language acquisition. Shanghai: Shanghai Foreign Language Education Press.

[10] Oxford, R. L. (1990). Language learning strategies: What every teacher should know. Beijing: Beijing World Publishing Corporation.

[11] Reutzel, D. R. Smith, J. A. \& Fawson, P. C. (2005). An evaluation of two approaches for teaching reading comprehension strategies in the primary years using science information texts. Early Childhood Research Quarterly 20, 276-305.

[12] Sheorey, R. \& Mokhtari, K. (2001). Measuring ESL students' awareness of reading strategies. Journal of Developmental Education 25.3, 2-10.

[13] Takallou, F. (2011). The effect of metacognitive strategy instruction on EFL learners' reading comprehension performance and metacognitive awareness. Asian EFL Journal 12.1, 272-300.

[14] Wen, Q.F. (2003). A successful road to English learning. Shanghai: Shanghai Foreign Language Education Press.

[15] Zhang \& Wu. (2009). Chinese senior high school EFL students' metacognitive awareness and reading-strategy use. Reading in a Foreign Language 21.1, 37-59.

Lixia Pei was born in Changzhou, China in 1983. She received her master degree in applied linguistics from Suzhou University, China in 2008. She is currently a lecturer in the School of Foreign Languages, Suzhou University of Science and Technology, Suzhou, China. Her research interests include Second Language Acquisition and English Testing. 